\title{
Studies on potential of Portland cement mortar for binding of waterworks sludge to reduce heavy metal leaching
}

\author{
PARAMALINGGAM THANALECHUMI ${ }^{1}$, ABDULL RAHIM MOHD YUSOFF $^{1,2, *}$, \\ MOHANADOSS PONRAJ ${ }^{3}$ and HANIM AWAB ${ }^{1}$ \\ ${ }^{1}$ Department of Chemistry, Faculty of Science, Universiti Teknologi Malaysia (UTM), 81310 Johor Bahru, \\ Johor Darul Takzim, Malaysia \\ ${ }^{2}$ Centre for Sustainable Nanomaterials, Ibnu Sina Institute for Scientific and Industrial Research, Universiti \\ Teknologi Malaysia (UTM), 81310 Johor Bahru, Johor Darul Takzim, Malaysia \\ ${ }^{3}$ Construction Research Centre (CRC), Faculty of Civil Engineering, Universiti Teknologi Malaysia (UTM), \\ 81310 Johor Bahru, Johor Darul Takzim, Malaysia \\ e-mail: rahim@kimia.fs.utm.my
}

MS received 17 February 2015; revised 27 August 2015; accepted 26 September 2015

\begin{abstract}
The investigation of heavy metal leaching and physicochemical properties of cement-solidified waterworks sludge (CMWWS) formed by incorporating waterworks sludge (WWS) into cement mortar was carried out. The chemical composition, compressive strength and other physicochemical properties of the CMWWS cube specimens were determined using field emission scanning electron microscopy (FESEM), X-ray diffractometry (XRD) and Fourier transform-infrared spectroscopy (FTIR). The major type of chemical components present in CMWWS was found to be Al and Fe. The increasing amount of WWS added to cement mortar resulted in the increasing of organic matter, urchin-like morphology and clear peak intensity. At the end of 28 days of curing, the soaking solution became strongly basic and CMWWS cube specimens leached out higher amount of heavy metals. The compressive strength of CMWWS increased up to a WWS percentage of $10 \%$, and basic $(\mathrm{pH}>7)$ curing solution was found to be better than water for curing purposes. It is concluded that solidification-stabilisation (S/S) technique is able to effectively reduce the leaching of heavy metals from the WWS and CMWWS containing up to $10 \%$ WWS can be used as construction material.
\end{abstract}

Keywords. Leaching; waterworks sludge; compressive strength; curing; solidification-stabilisation.

\section{Introduction}

Alum is generally used as a primary coagulant in the production of clean drinking water $[1,2]$. This results in the generation of significant quantities of waterworks sludge (WWS), which is a by-product of the processing of drinking water in water treatment plants $[3,4]$. In recent years, the management of WWS has become an environmental issue due to the enormous quantities generated and the associated costs of disposal $[4,5]$. WWS is considered a waste which cannot be processed through traditional sewage sludge disposal methods and in many cases goes to landfill $[6,7]$. In Malaysia, WWS is classified as schedule waste, cannot be discharged into streams and is governed by stringent regulations on waste management by the Department of Environment [8]. The Semanggar water treatment plant in Kota Tinggi, Johor, Malaysia, has a 40-acre landfill area, accommodates as much as 120 tonnes of raw sludge and

*For correspondence generates an estimated 80 tonnes of dried sludge per year. Although studies have shown that heavy metals in the WWS generated by some water treatment plants in Malaysia are within safe limits [9], the accumulation of heavy metals in landfills is still a concern [10]. Options for reusing WWS as absorbent for dye removal [11, 12], mercury [13] and phosphorous studies [14] have been reviewed. In addition, utilization of WWS in the production of construction materials has been thoroughly investigated. A study conducted by Babatunde and Zhao [6] presented about constructive approaches of reuse of water treatment sludge in various categories including construction materials. However, option of using the solidification-stabilisation (S/S) technique, to incorporate Malaysian WWS into cement mortar (CM) to produce a cement mortar-waterworks composite referred to as cement-solidified waterworks sludge (CMWWS) for use as a construction material has not been studied. The S/S often immobilizes contaminants (such as heavy metals) within a waste material (such as sludge) to form a solid. This technique may involve a 
chemical reaction between the waste and solidifying reagent or by mechanical processes. In this study, the process is the mechanical binding of mortar to the sludge material. Therefore, this study aimed to examine the structure and physicochemical properties of CMWWS, to investigate the leaching properties of this material and to identify the factors that affect the strength of CMWWS.

\section{Experimental}

\subsection{Materials and instrumentation}

Raw WWS (as shown in figure 1a, b) was collected from the Semanggar water treatment plant, Kota Tinggi, Johor, Malaysia. The sludge was dewatered, air-dried and ground. A cement mixer was used for mixing purposes. CMWWS cube specimens $(50 \times 50 \times 50 \mathrm{~mm})$ containing WWS and CM were cast according to the standard method (BS 4550: Part 3: Section 3.4:1978). The cube specimens contained varying ratio of sludge as additive to OPC $(5 \%, 10 \%$ and $20 \%$ sludge) and a constant water-to-cement ratio of 0.45 .

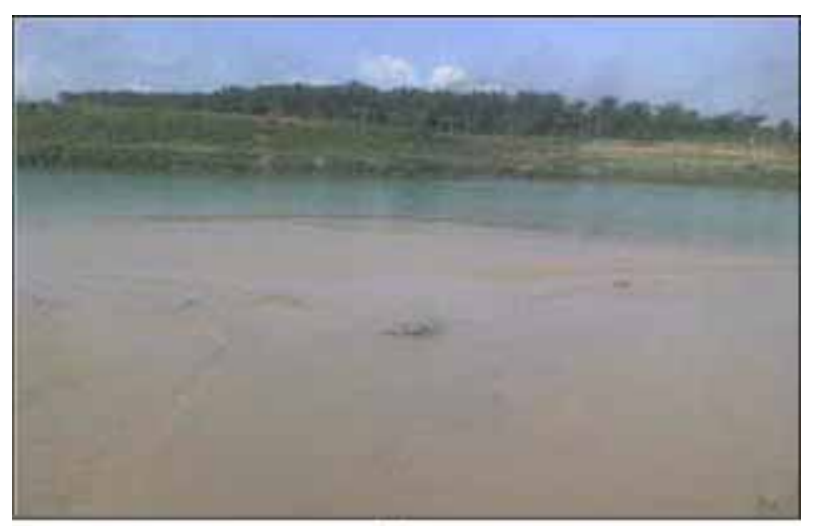

(a)

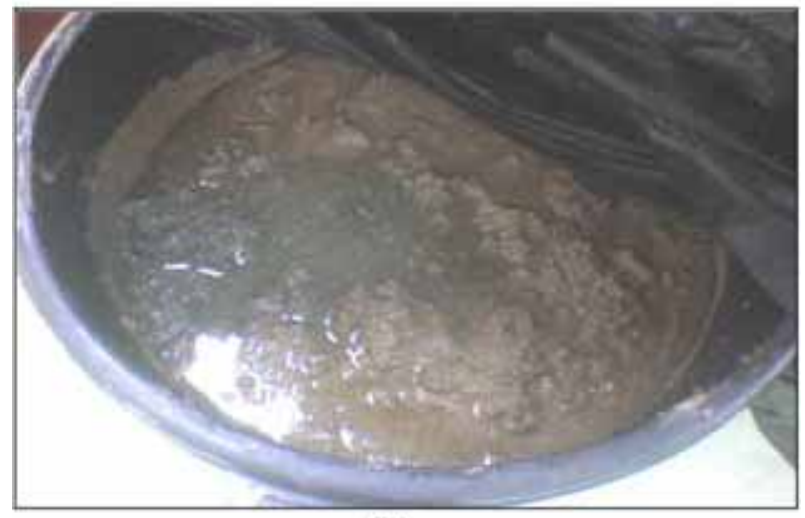

(b)

Figure 1. (a) Photographic view of WWS storage lagoon located at Semanggar water treatment plant, (b) WWS sampling for experiment.
Leaching tests were performed on the CMWWS cube specimens after $24 \mathrm{~h}$ of hardening using distilled water and $0.1 \mathrm{M}$ of acetate buffer and ammonium hydroxide buffer solutions as eluents. Flame Atomic Absorption Spectroscopy (FAAS, Perkin-Elmer Analyst 400), a quantitative analysis was achieved by measuring the absorbance of a series of solutions of known concentration of each metal. A calibration curve and the equation for the line for each metal were plotted and used to determine an unknown metal concentration of based on its absorbance. The FAAS instrument setting and operational conditions were done in accordance with the manufacturers' specifications. The levels of the metals that leached out were determined using FAAS. The metal compositions of the cube specimens were determined by wet digestion followed by analysis using FAAS. The cube specimen samples were then cured in air tight containers which were filled of distilled water, acetate buffer and ammonium hydroxide buffer separately. After 7 or 28 days of curing, the cube specimens were tested for compressive strength using the standard method, ASTM C 109. The evaluation of the effects of the curing solution on the heavy metal leaching from the CMWWS cube specimens and on the $\mathrm{pH}$ (pH meter CyberScan, Model 500) was performed by determining the levels of heavy metals in the curing solutions at selected intervals over a period of 28 days of the curing process. The $\mathrm{pH}$ and metal leaching of powdered CMWWS sample was evaluated in a similar manner.

\subsection{Sample preparation}

Thermal analysis on WWS was conducted using thermogravimetric analyzer (TGA, Metler-TA 4000). For this analysis, about $10 \mathrm{mg}$ of powdered samples was heated in range of temperature $20-800{ }^{\circ} \mathrm{C}$ at constant rate of $10{ }^{\circ} \mathrm{C} \mathrm{min}{ }^{-1}$ in nitrogen atmosphere. Fourier transform infrared (FTIR) Spectrometer (Shimadzu 8300) was applied to study on the molecular bonds of the samples. A small amount (about $1 \mathrm{mg}$ ) of sample was mixed well with $100 \mathrm{mg}$ of potassium bromide $(\mathrm{KBr})$ to form a free powder mixture with a ratio of 1:100 and it was compressed into a thin plate under a pressure of 7 tonnes for $3 \mathrm{~min}$. Then, the thin and transparent palette was used for FTIR analysis. The morphological structures of the samples were examined by field emission scanning electron microscopy (JEOL JEM-2300) where the sample was spread evenly onto small aluminium stubs via double-sided tape. Gold coating was carried out so that the images can be seen distinctively. The phase identification of WWS and CMWWS cube specimens was studied using X-ray diffractometry (XRD, Siemens D5000). The powdered samples which were dried in the oven for overnight were analyzed with $\mathrm{CuK}_{\alpha}$ radiation over $2 \theta$ from 2 to $6{ }^{\circ} \mathrm{C}$ at step width of 0.04 and step time of $0.5 \mathrm{~s}$. 


\section{Results and discussion}

\subsection{Physiochemical characteristics}

The chemical composition of WWS, CM and CMWWS cube specimens containing 5\%,10\% and $20 \%$ sludge in cement-mortar is shown in figure $2 . \mathrm{Al}$ and $\mathrm{Fe}$ are the dominant components present in the WWS and also in CM and all the CMWWS samples, where Al was almost twice the amount of $\mathrm{Fe}$. The amount of $\mathrm{Al}$ was greatly increased after addition of the WWS into the CM. This was due to the high $\mathrm{Al}$ content in the $\mathrm{CM}$ contributed by the components such as sand and cement which are also high in terms of metal contents. Similar to CM, the CMWWS cube

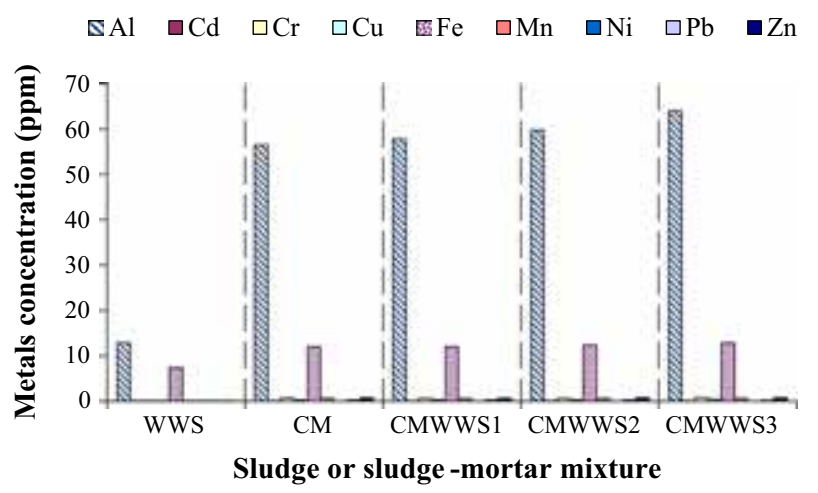

Figure 2. Chemical compositions of the WWS, CM and CMWWS cube specimen. specimens contained relatively high levels of $\mathrm{Al}$ and $\mathrm{Fe}$ contributed by the sand, cement and WWS, which also contain high levels of $\mathrm{Fe}$ and Al. In addition, the WWS already had huge amount of $\mathrm{Al}$ because of the alum that used as coagulant in the water treatment plant. The addition of $>10 \%$ WWS to the CM slightly increased the amount of $\mathrm{Al}$ and $\mathrm{Fe}$ compared with the levels of these elements in $\mathrm{CM}$. This trend of increased metal content was also observed for other minor metals such as $\mathrm{Cd}, \mathrm{Cr}, \mathrm{Cu}, \mathrm{Mn}, \mathrm{Pb}$ and $\mathrm{Zn}$.

The thermal stability for WWS was studied using TGA. The profile of WWS weight loss exhibited two stages during this thermal analysis as shown in figure 3 . From the thermogram, it can be clarified that an approximately $2 \%$ weight loss of WWS was detected between the temperatures of 260 and $290{ }^{\circ} \mathrm{C}$, and about $8.3 \%$ weight loss between 460 and $540{ }^{\circ} \mathrm{C}$ which indicated that approximately one-tenth of the WWS contained some component(s) with lower thermal stability presumably organic compounds [15].

The physical and structural properties of the $\mathrm{CM}$ and CMWWS cube specimens were investigated using FTIR, FESEM and XRD. Figure 4 shows FTIR spectrum of CM and CMWWS obtained by using $\mathrm{KBr}$ disc (CM: $\mathrm{KBr}, 1: 100$ and CMWWS: $\mathrm{KBr}, 1: 100)$. The IR spectra for $\mathrm{CM}$ and CMWWS were similar, indicating the presence of similar type of organic matter. The IR spectrum shows that the $\mathrm{O}-\mathrm{H}$ peak intensity in the range of $3400-3700 \mathrm{~cm}^{-1}$ for the CMWWS is generally broader than the sharp peaks of the WWS. It was suggesting the presence of an amorphous

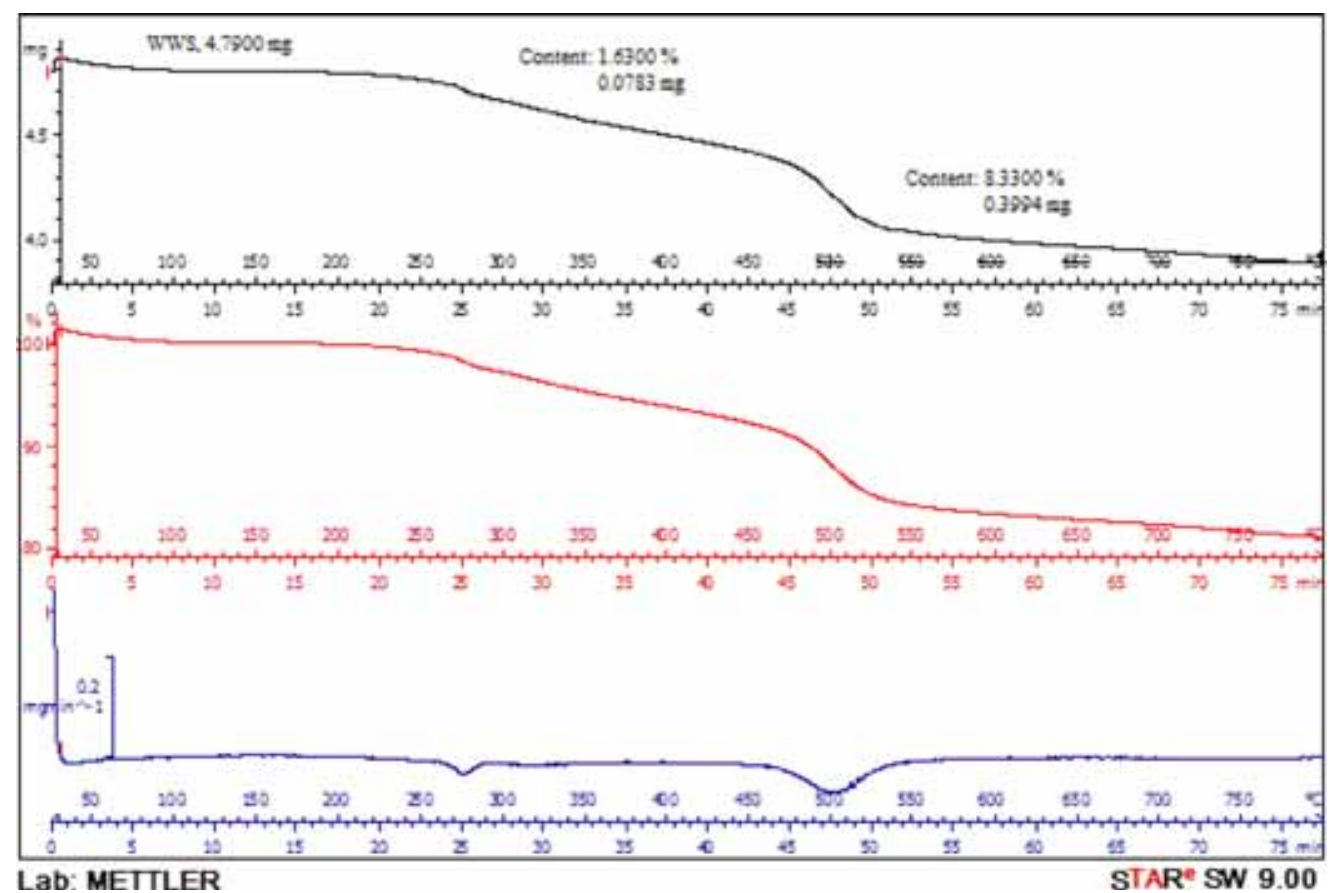

Figure 3. TGA curve of WWS. 


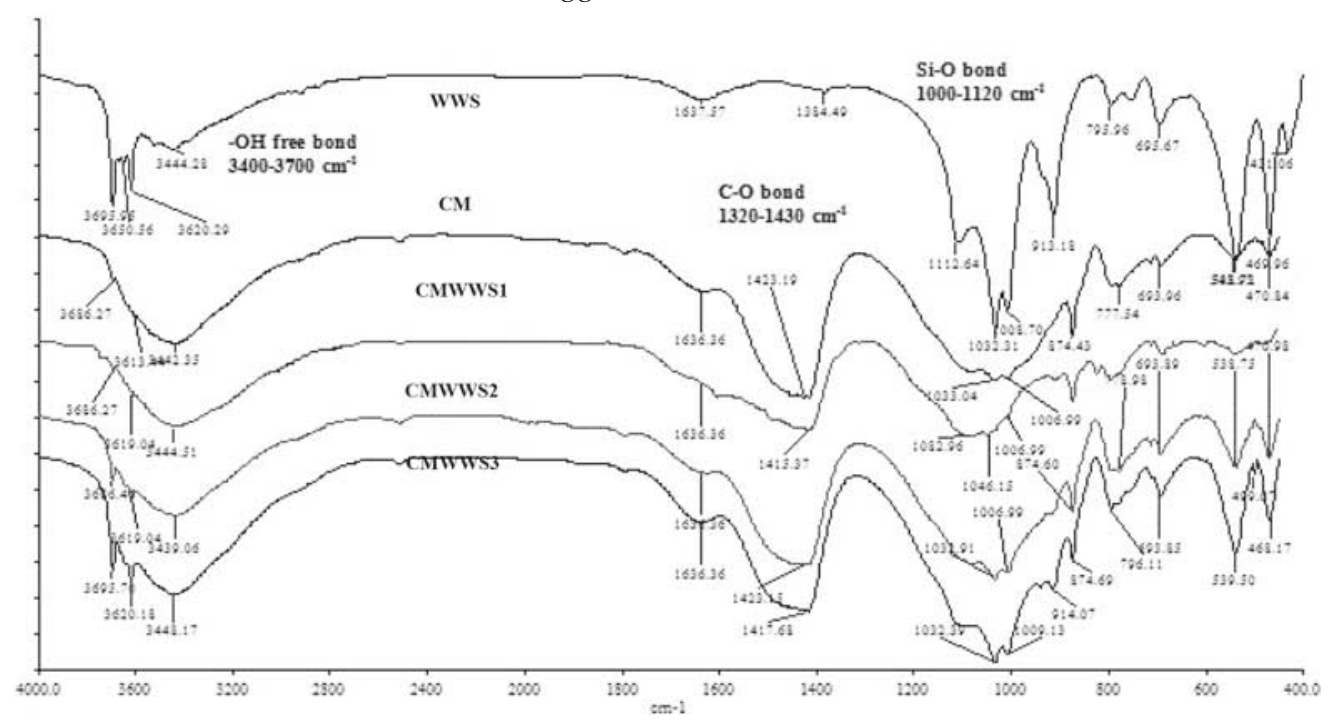

Figure 4. FTIR spectra of CM and CMWWS cube specimen. Note: CMWWS1, CMWWS2 and CMWWS3 contained 5\%, 10\% and $20 \%$ WWS, respectively.

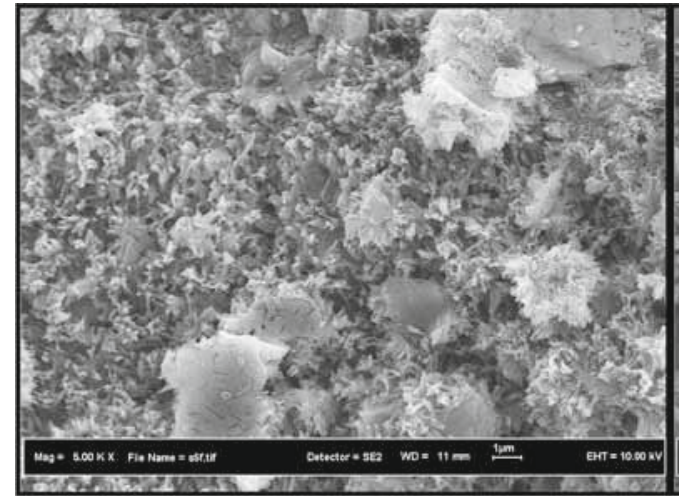

(a)

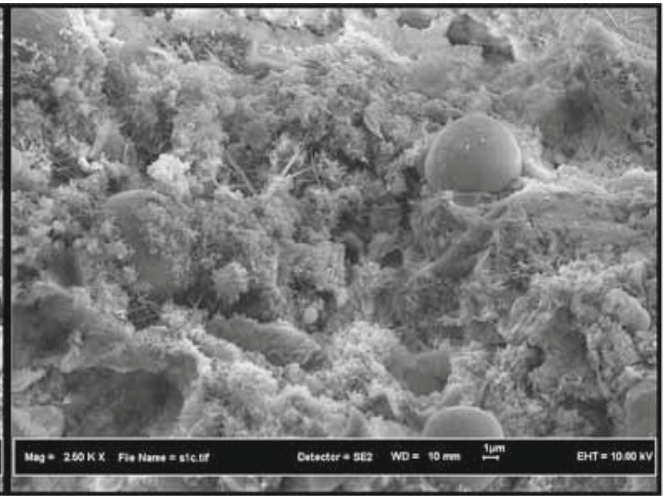

(b)

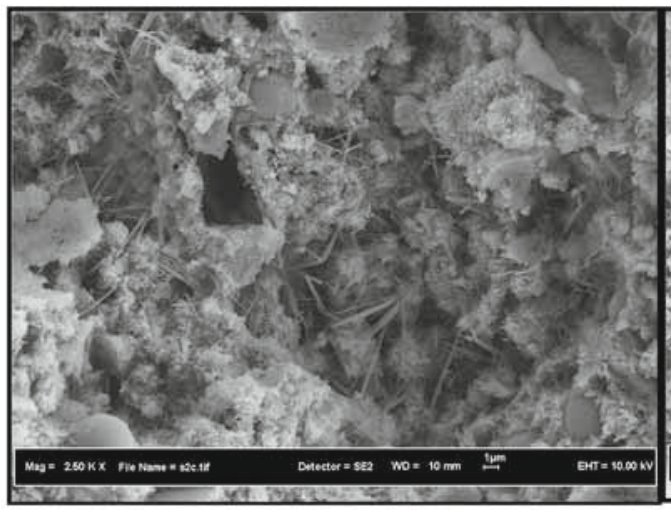

(c)

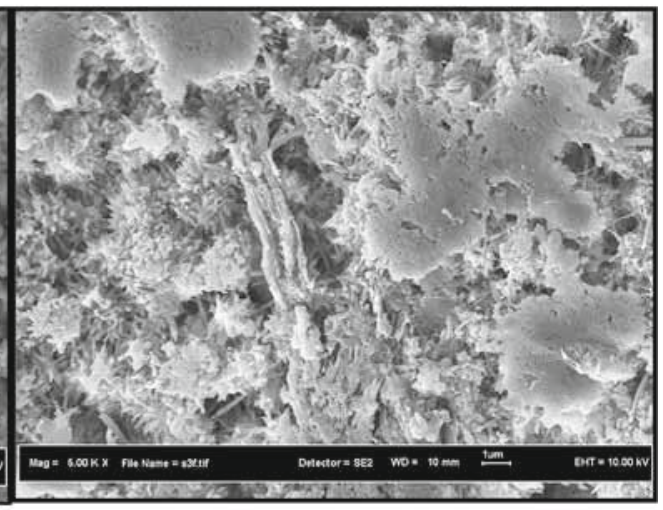

(d)

Figure 5. FESEM micrographs (a) CM, (b) CMWWS1, (c) CMWWS2, (d) CMWWS3 cube specimen. Note: CMWWS1, CMWWS2 and CMWWS3 contained 5\%, 10\% and 20\% WWS, respectively. 


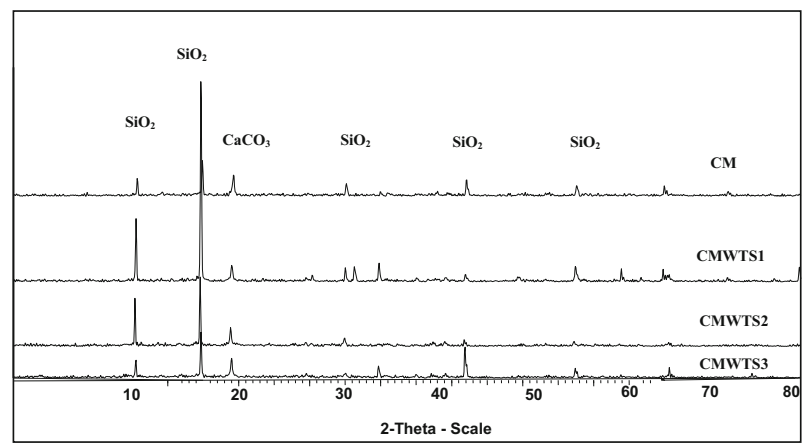

Figure 6. X-ray diffraction pattern of CM and CMWWS cube specimen.

silicate material or possibly hydrated aluminum silicates. The band at $1636 \mathrm{~cm}^{-1}$ is attributed to the bending mode of $\mathrm{H}_{2} \mathrm{O}$ molecules. A band at $1000-1085 \mathrm{~cm}^{-1}$ is observed due to $\mathrm{Si}-\mathrm{O}-\mathrm{Si}$ asymmetric stretching vibrations of silica. The range of bands at $770-796$ and $460-500 \mathrm{~cm}^{-1}$ could be assigned to quartz and silica, respectively.

Figure 5 shows FESEM micrographs of $\mathrm{CM}$ and CMWWS. A high resolution surface imaging with the accelerating voltage of $10 \mathrm{kV}$ and $10 \mathrm{~mm}$ working distance was used for the FESEM analysis. The magnification of the samples images was between 2500 and 5000 times. The FESEM micrographs can be used to compare or monitor the development of the micro-structure of samples containing WWS. It also shows that the morphology of $\mathrm{CM}$ and CMWWS is urchin-like. The urchin-like morphology of the CMWWS became clear along with the increase of WWS in the mixture. The structure of CM and CMWWS was not homogeneous due to non-identical particle shape and size.

To identify the components and minerals in the samples made from cube specimens, they were subjected to XRD analysis. The X-ray diffractogram shown in figure 6 indicates that CMWWS and the CM consist of polycrystalline and poorly ordered particles. The fitting of the diffractogram to the data available in the XRD catalogue revealed the presence of calcite and quartz, which are the major minerals present in cement, sand and sediment $[16,17]$. The major mineral in cement, $\mathrm{Ca}(\mathrm{OH})_{2}$ was not obviously observed due to very intense peak of quartz from sand. Possibly, it can be stated that the carbonation reaction had occurred and is proven by the presence of calcite peak [18]. The Alite, $\mathrm{C}_{2} \mathrm{~S}$ and Belite, $\mathrm{C}_{3} \mathrm{~S}$ peaks also would not be noticeable in hydrated cement [19]. Although the diffraction peaks were located at different $2 \theta$ values (range $=20^{\circ}-75^{\circ}$ ), the intensity of the peak decreased along with the increasing percentage of WWS in the mixture (CMWWS3 < CMWWS2 < CMWWS1).

\subsection{Effect of $p H$ changes}

The $\mathrm{pH}$ of the curing solution was determined at the selected time points $(1,3,7,14$ and 28 days) during curing.

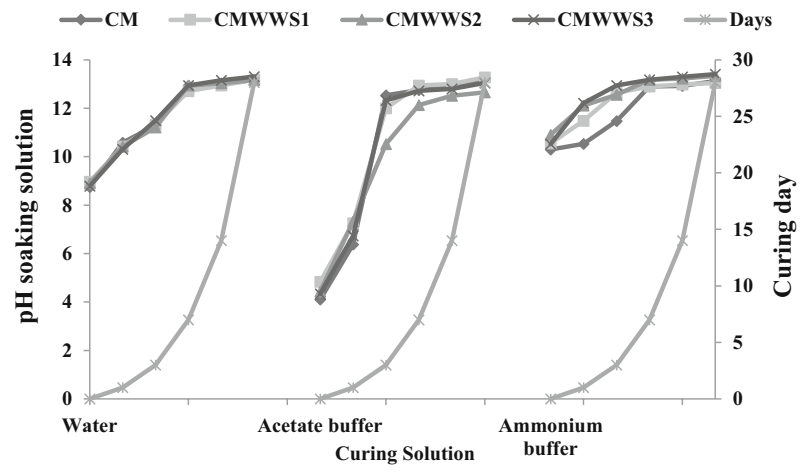

Figure 7. The effects of curing solution and curing time on the $\mathrm{pH}$ of CM and CMWWS cube specimen.

Figure 7 illustrates the effect of curing solution (distilled water, $0.1 \mathrm{M}$ acetate buffer and $0.1 \mathrm{M}$ ammonium hydroxide buffer) and the curing time of the sample $\mathrm{pH}$. The usages of buffers as curing solutions were focused on the effectiveness of cement as binder to the metals and preventing it from leaching out at different condition $(\mathrm{pH}$ medium). The results show that $\mathrm{pH}$ of the curing solution was found to be strongly basic at the end of the 28th-day of curing period, even though the $\mathrm{pH}$ was initially different. This change was more obvious for the acetate buffer because the initial $\mathrm{pH}$ of this buffer was acidic $(\mathrm{pH} 4)$. As the curing time increased, the $\mathrm{pH}$ became stabilized. The final $\mathrm{pH}$ of the cube specimen is important, because the basic $\mathrm{pH}$ indicates that the metal ions got immobilised in the cube specimens and are present in the form of precipitates, therefore the level of metal ion leaching should be lower.

\subsection{Heavy metal leaching}

The effect of curing time and curing solution on the leaching of heavy metals from the intact CMWWS cube specimens samples is illustrated in figurers 8 and 9. The curing solution was tested for heavy metal using FAAS after 7 and 28 days in order to determine the amount of metals that had been leached out from the intact CMWWS cube specimens. According to standard method, BS 4550: Part 3: Section 3.4: 1978, the curing process for bricks should be conducted after $24 \mathrm{~h}$ of hardening. The compressive strength test was conducted on 7 and 28 days of curing to ascertain the strength gain as a function of time. In addition, some metals might be leached out during the early stage of curing process so that determination on metals leaching at early stage was conducted. For all the metals except $\mathrm{Al}, \mathrm{Pb}, \mathrm{Fe}, \mathrm{Ni}$ and $\mathrm{Cr}$, the results showed that lower level of metal leaching occurred due to the incorporation of WWS into the $\mathrm{CM}$. Although $\mathrm{Al}, \mathrm{Pb}, \mathrm{Fe}, \mathrm{Ni}$ and $\mathrm{Cr}$ exhibited visible leaching along with time, but the amount of these metal that leached was found to be smaller. Overall, the results showed that the amount of metal that 


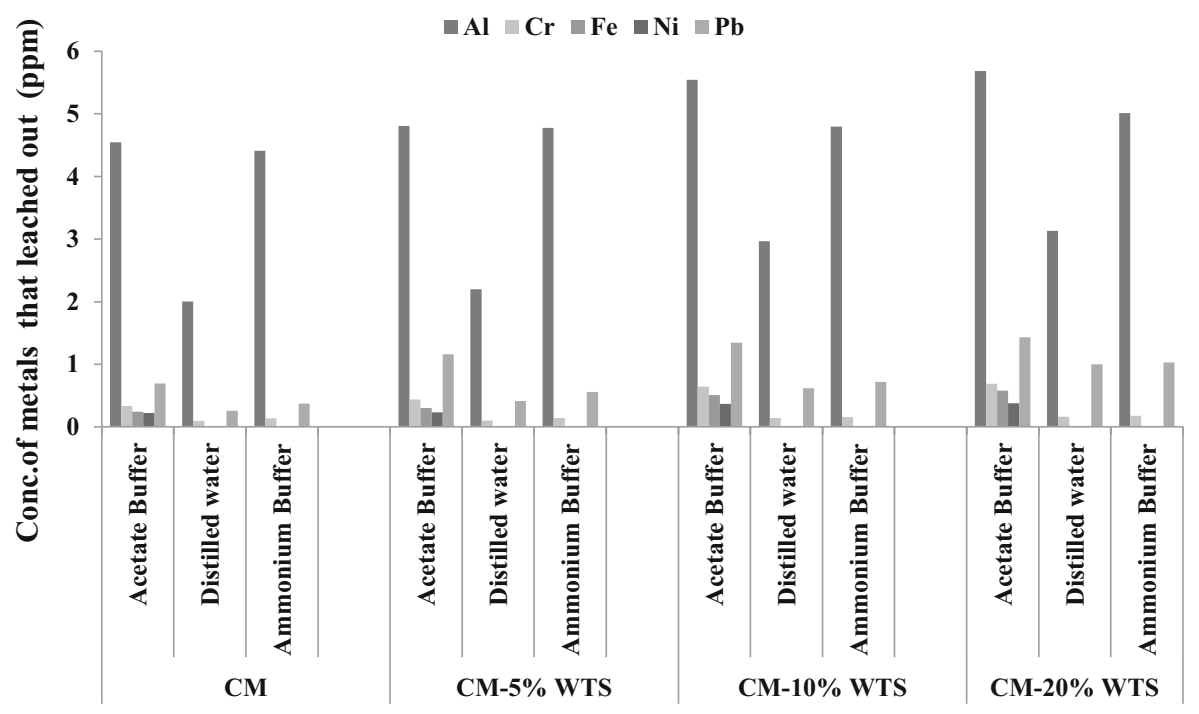

(a)

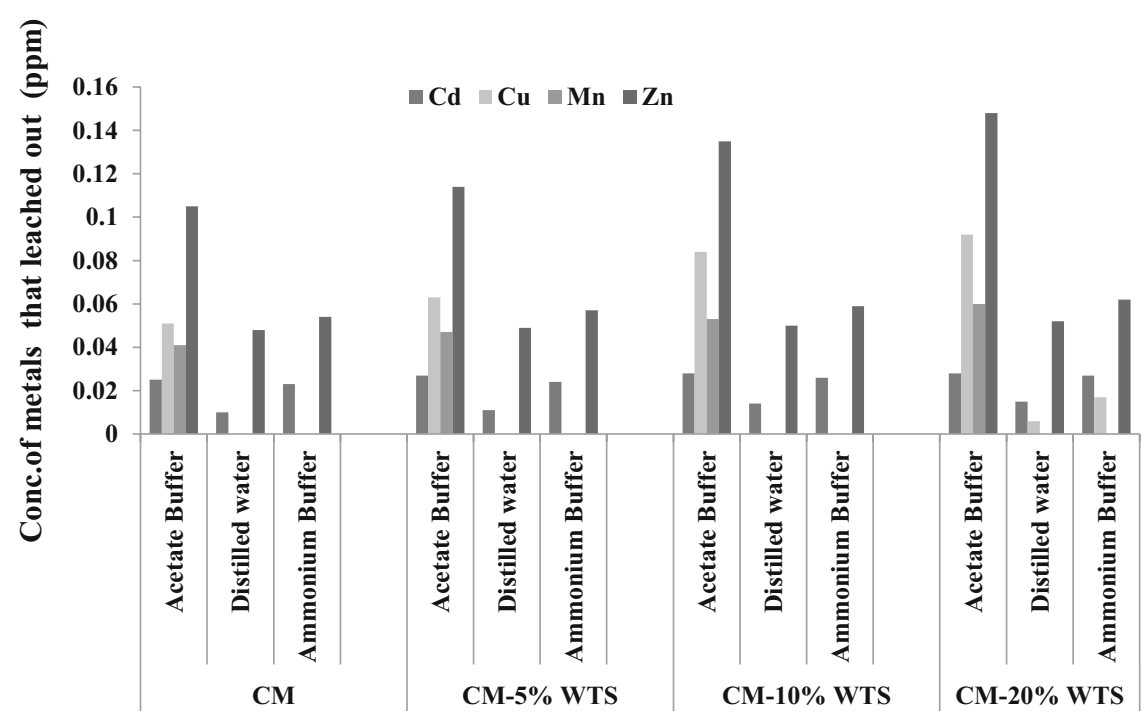

(b)

Figure 8. Effects of 7-days curing duration and the curing solution on the leachability of metals from CM and CMWWS cube specimen.

leached out using curing solution increased with time. The level of leaching was found to be higher in acetate buffer, followed by ammonium hydroxide and water. The highest amount of metal to leach out was $\mathrm{Al}$, because the main component of CMWWS is Al. As for the CMWWS cube specimens, the order of metals leaching in the curing solutions was acetate buffer $>$ ammonium hydroxide buffer $>$ water. The order for the amount of metal that leached out was $\mathrm{Al}>\mathrm{Pb}>\mathrm{Cr}>\mathrm{Fe}>\mathrm{Ni}$. Other metals that leached out in the form of trace amounts could not be detected (ND) by FAAS.
The higher amount of $\mathrm{Al}$ and $\mathrm{Fe}$ attributes to the chemical composition of WWS. It can be concluded that the $\mathrm{S} / \mathrm{S}$ technique was most effective in decreasing the leaching out of $\mathrm{Cr}$, as indicated with the decreasing amount of $\mathrm{Cr}$ in the acetate buffer when the percentage of WWS was increased. In general, these results indicate that the incorporation of WWS into the cement using S/S technique was effective in reducing the leaching out of metals from WWS. The metals initially present in the WWS were immobilised in the CMWWS cube specimens, thus reducing the leaching of heavy metals. 


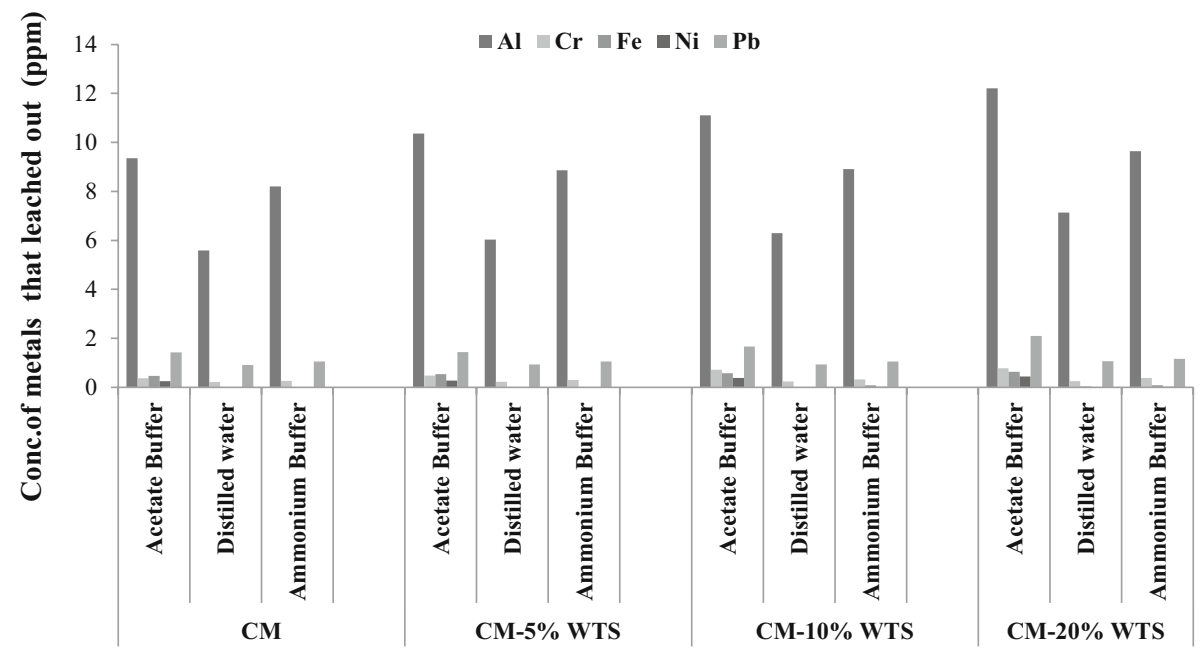

(a)

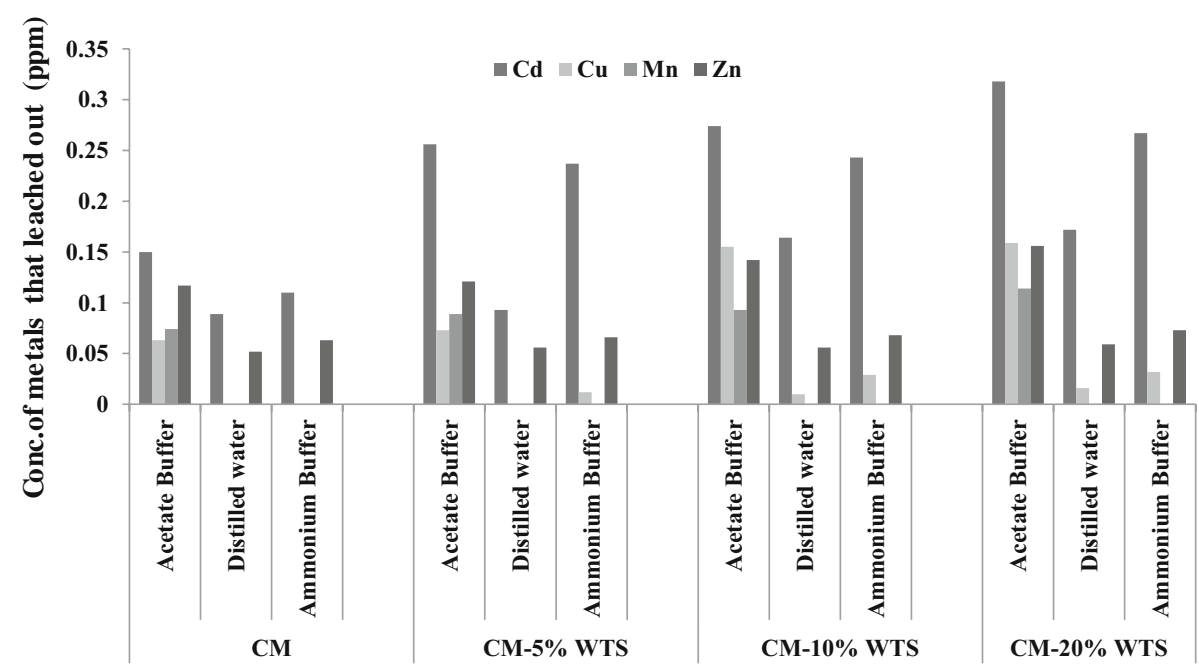

(b)

Figure 9. Effects of 28-days curing duration and the curing solution on the leachability of metals from CM and CMWWS cube specimen.

\subsection{Compressive strength}

The potential of using CMWWS as a raw material for construction was further investigated by performing the standard compressive strength test on CMWWS cube specimens as shown in figure 10a. The effect of curing time, $\mathrm{pH}$, curing solution and percentage of WWS on the compressive strength of CMWWS cube specimens is illustrated in figure 10b. The results show that the factors contributing to the compressive strength of the cube specimens are due to the percentage of WWS in the cube specimen, curing time and $\mathrm{pH}$ of the curing solution. The increasing percentage of WWS in the CMWWS reduced the compressive strengths of the cube specimen due to the loss of cohesive bond strength caused by the displacement of main minerals in the cement by other compounds such as fine inorganic particles flocs and other organic debris present in the CMWWS [15]. In addition, as more $\mathrm{Al}$ leached out of from the CMWWS, the porosity of the material increased; causing the CMWWS samples have lower compressive strength values. The longer the curing time, the higher the compressive strength of the CMWWS cube specimens was obtained. The compressive strength of the cube specimen increased along with the increasing $\mathrm{pH}$ of the soaking solution, as shown in most of the studies involving cement [19]. The results of the present study indicate that for using CMWWS as construction material, the percentage of WWS in the CMWWS must not exceed $10 \%$, as higher percentage makes the material more porous. A basic $(\mathrm{pH}>7)$ curing solution is found to be better than water. Curing in acidic solution not only reduces the strength of the CMWWS cube specimens but also may result in the increasing of heavy metals. 


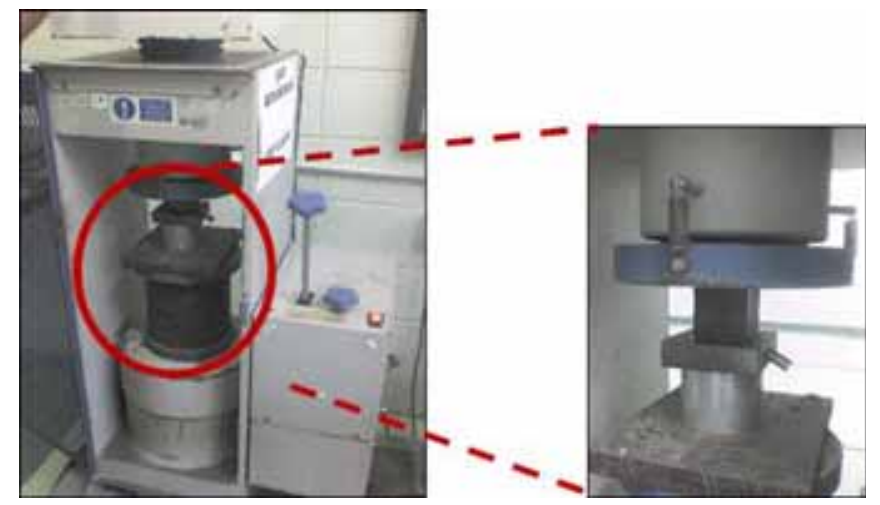

(a)

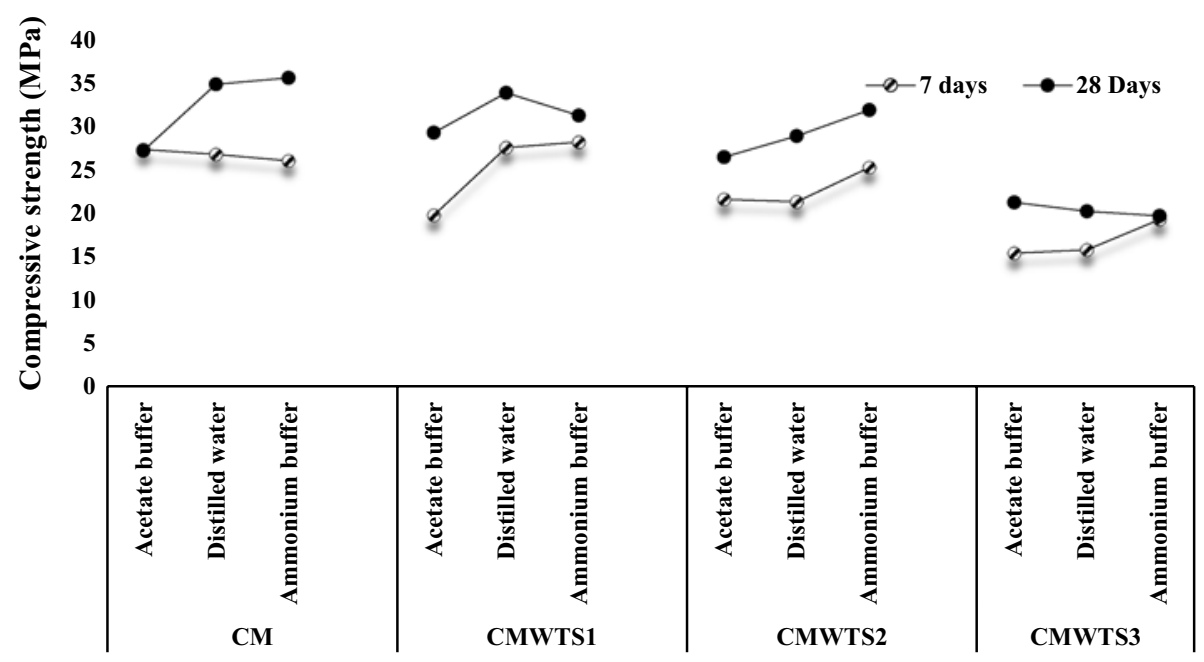

(b)

Figure 10. (a) Compressive strength tester, (b) compressive strength of CMWWS cube specimen as function of the percentage of WWS and $\mathrm{pH}$.

\section{Conclusion}

The CM and CMWWS showed the presence of similar level of organic matter as demonstrated with the identical IR spectral pattern. The urchin-like morphology of CM and CMWWS became clear with the increasing of WWS. Higher amount of metals were found to leach out of CMWWS cube specimens in the acidic solution (low $\mathrm{pH}$, acetate buffer), followed with the basic solution (high $\mathrm{pH}$, ammonium hydroxide) and neutral solution (neutral $\mathrm{pH}$, water). The compressive strength of CMWWS cube specimens increased along with the prolonged curing time and increasing $\mathrm{pH}$ in the curing solution. In contrast, increasing the content of WWS in CMWWS reduced the compressive strength of the cube specimens. The CMWWS in order to be used as construction material, the percentage of WWS added to the CM must not exceed $10 \%$, and the material must not be cured in the acidic medium. In this study, the application of S/S technique to WWS using cement as the stabilising medium was demonstrated to be a potentially effective method to reduce heavy metal leaching from the WWS. In addition it can be mentioned that CMWWS has the potential to be used as a construction material.

\section{Acknowledgements}

The authors are wish to thank Universiti Teknologi Malaysia for the financial support (Research University Grant, GUP, Q.J130000.7126.01J51) and Zamalah scholarship.

\section{References}

[1] Greenwood N N and Earnshaw A 1997 Chemistry of the elements. Oxford: Butterworth Heinemann

[2] Jones P H and Tompeck M A 2006 Water treatment: Encyclopedia of environmental science and engineering, 5th edition, Boca Raton, FL: CRC Press 
[3] Maha Alqam, Ahmad Jamrah and Haya Daghlas 2011 Utilization of cement incorporated with water treatment sludge. Jordan J. Civil Eng. 5: 268-277

[4] Victoria A N 2013 Characterisation and performance evaluation of water works sludge as bricks material. Int. J. Eng. Appl. Sci. 3: 69-79

[5] Zaboon S M 2011 Aluminum leachability evaluation from oven dried alum sludge. Iraqi J. Chem. Petrol. Eng. 12: 25-33

[6] Babatunde A O and Zhao Y Q 2007 Constructive approaches toward water treatment works sludge management: An International review of beneficial reuses. Critical Rev. Environ. Sci. Technol. 37: 129-164

[7] Jangkorn S, Kuhakaew S, Theantanoo S, Klinla-or H and Sriwiriyarat T 2011 Evaluation of reusing alum sludge for the coagulation of industrial wastewater containing mixed anionic surfactants. J. Environ. Sci. 23: 587-594

[8] DOE 2005 Environmental Quality Act (Scheduled Waste) Regulation. Department of Environment, Ministry of Natural Resources and Environment Malaysia

[9] Aminnudin M B 2009 Study on characteristic, treatment and disposal of drinking water treatment plant residue. In: Proceedings of Water Malaysia 2009: ICIBP2009 - International Conference on Industry Best Practice, 19-21 May 2009. Kuala Lumpur, Malaysian Water Association (MWA)

[10] Awab H and Paramalinggam T 2011 Mussel shell and waterworks sludge as sorbent materials for the removal of $\mathrm{Cu}$ (II) from aqueous solution. J. Fundam. Sci. 7: 113-119

[11] Kayranli B 2011 Adsorption of textile dyes onto iron based waterworks sludge from aqueous solution; isotherm, kinetic and thermodynamic study. Chem. Eng. J. 173: 782-791
[12] Sadri Moghaddam S, Alavi Moghaddam M R and Arami M 2010 Coagulation/flocculation process for dye removal using sludge from water treatment plant: Optimization through response surface methodology. J. Hazard Mater. 175: 651-657

[13] Hovsepyan A and Bonzongo J C 2009 Aluminum drinking water treatment residuals (Al-WTRs) as sorbent for mercury: Implications for soil remediation. J. Hazard Mater. 164: 73-80

[14] Babatunde A O, Kumar J L G and Zhao Y Q 2011 Constructed wetlands using aluminium-based drinking water treatment sludge as P-removing substrate: Should aluminium release be a concern. J. Environ. Monit. 13: 1775-1783

[15] Vesilind P A, Hartman P A and Skine E T 1986 Sludge processing and disposal. Bruce A M, Colin F and Newman P J (eds.) USA Lewis Publishers. pp 170-183 (Chapter 16)

[16] Oladoja N A and AliuY D 2009 Snailo shell as coagulant aid in the alum sludge precipitation of malachite green. $J$. Hazard Mater. 164: 1496-1502

[17] Ramasamy V and Suresh G 2009 Mineral characterization and crystalline nature of quartz in Ponnaiyar River sediments, Tamilnadu, India. Am-Euras J. Sci. Res. 4: 103-107

[18] Gabrovsek R, Vuk T and Kaucic V 2006 Evaluation of the hydration of Portland cement containing various carbonates by means of thermal analysis. Acta Chim. Slov. 53: 159-165

[19] Zaiton Abdul Majid 2004 Stabilization/solidification of toxic and hazardous waste: Engineering and chemical consideration. Thesis submitted in partial fulfillment of the requirement for the award of Doctor of Philosophy of Universiti Malaya, Malaysia 